\title{
USING UP-TO-DATE DIGITAL APPLICATIONS FOR TEACHING FOREIGN LANGUAGES
}

\author{
Mamonov Alexander Olegovich \\ English and French Teacher, \\ Expert in international economic relations \\ Moscow, Russia
}

\begin{abstract}
This article is devoted to using existing digital applications in foreign language teaching practice. The review of the existing digital applications is performed. The current study applies qualitative methodology to explore the opportunities of digital applications for foreign language teaching. The study proposes the ways such modern applications can be used for teaching foreign languages. Further research in the same area of study is necessary to develop practical exercises and assess their effectiveness.
\end{abstract}

Keywords: digital technology, platform, modern application, education, foreign language

\section{Introduction}

At present the role and status of English remains to be that of the international language, the language of media, library, communication and business. The growing number of English speakers made it necessary to improve its teaching using contemporary digital technologies.

As the digital era approached, it started to gradually affect the education system. A shift caused by CDs was tremendous, still it was followed by that of smartphones and web services. The 2010s can be considered the decade of the digital devices entering the education system. These years are characterized with a boom and growth of not only educational digital resources, but also websites and applications. Existing applications become available on multiple platforms for PC and smartphone devices, namely Android and iOS.

The shift present the topicality of studying the existing applications for learning English and their use from the pedagogical perspective. 


\section{Existing applications for learning English}

Teachers indicate that the use of technology has an important impact on student's second language learning (Abbasova, 2019). "Technology has turned into one essential aspect of society that helps students to understand the bigger picture of the world and not just stay confined to what schools and teachers teach them within their classrooms" (Warschauer, 2000).

The existing web services and applications are of special interest for scholars to investigate it further. Still, first it is necessary to consider some of them in more detail.

\section{FluentU}

FluentU is a service and an app which provides learners with real life world videos. It is an outstanding learning and teaching tool on its own. It can be considered to serve also as a great source of meaningful and interesting supplementary materials. The service provides videos, trailers, quizzes and other authentic language learning materials and can be accessed from any device.

The website is available in English, Korean and Japanese, which may require using Google Chrome to translate it and navigate in other languages. Audio dialogues are downloadable for listening them offline.

The captions are subtitled and translated so the user can perform a click to see an in-context definition, along with example sentences. The effect is achieved through vivid and true-to-life scenarios.

\section{DuoLingo}

DuoLingo is an effective free language-learning platform for beginning learners. It is also applied for an after-class review of important grammar and vocabulary topics.

Duolingo can be regarded as that with the features of a game simulator. A reward system in which users acquire "lingots" and an in-game currency that can be spend on features such as character customizations or bonus levels available on the mobile app makes this platform a gamification platform. 
The platform uses the concept of public leaderboards to create the feeling of competing against their virtual friends and other users. The level system combines experience points and skill level. Badges in Duolingo represent achievements that are earned from completing specific objectives or challenges.

The study process created with Duolinguo is methodologically rich, combining such methods as listening to the pronunciation, reading sentences, talking with language bots and voice recording, forming phrases by ordering words, matching images to words and other.

\section{Memrise}

Memrise is a language platform that uses spaced repetition of flashcards to increase the rate of learning. This platform can be used as a learning tool on a smartphone app and as a browser-based web app.

The courses within Memrise are designed to teach languages, although used for other academic and nonacademic contents.

The technology of "vivid encoding" can be recognized as the main feature of Memrise. The concept of plants is used to systematically remind users to attend to

the words or phrases they have "planted" appealing to the emotions of the learner.

The platform is widely criticized as being too focused on words while other aspects of knowledge and skills are completely ignored.

Some other popular applications and platforms that can be used for teaching / learning languages are presented on picture 1 . 


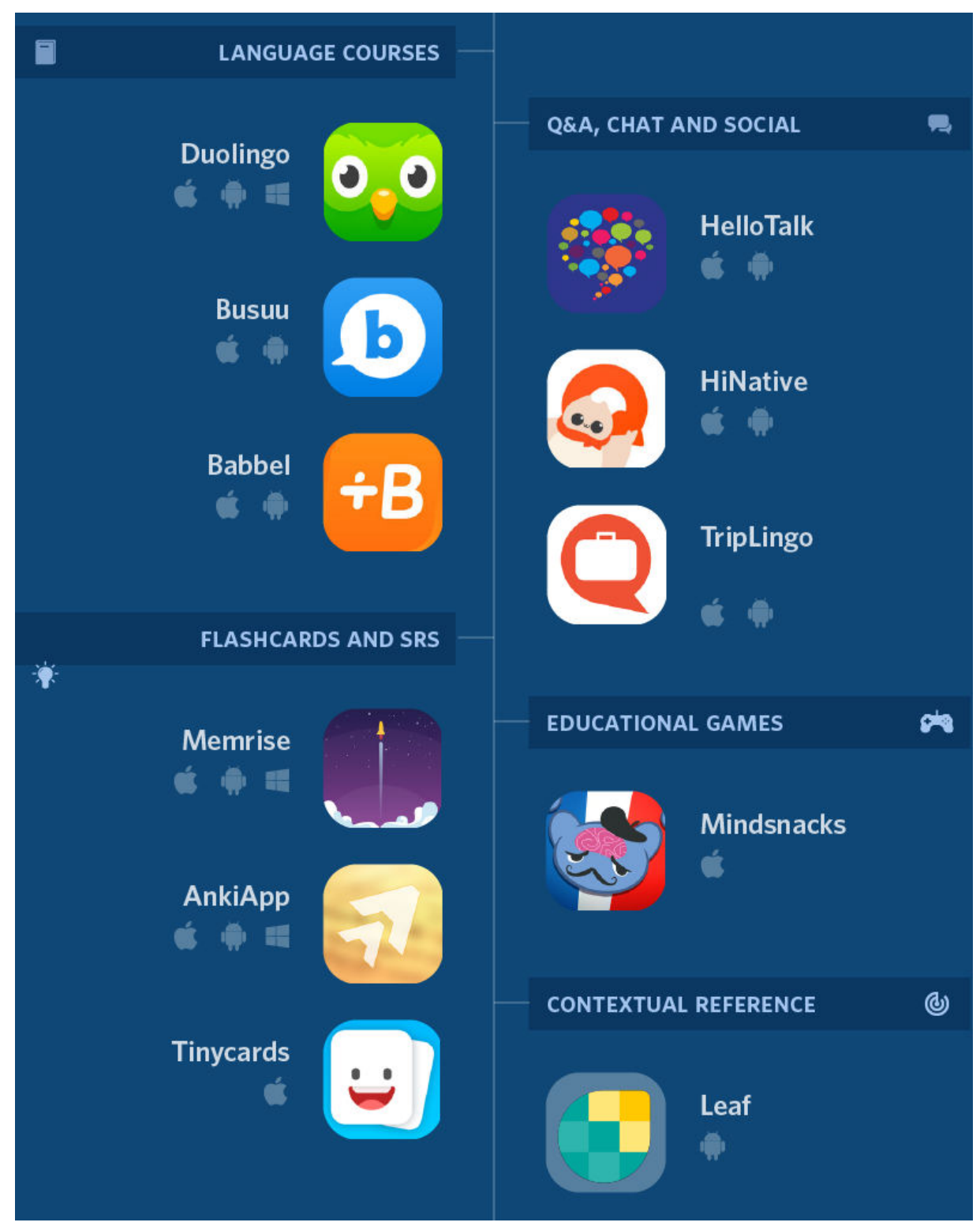

Picture 1. Digital applications and platforms for learning foreign languages

\section{Ways to use modern applications for teaching foreign languages}

The modern pedagogy employs its best classical practices and tries to develop and combine them with new methods and principles to organize education in the more effective way.

Considering new applications and web services is a long and gradual process for them to be a quality tool for teaching. Using these services can help us (1) to organize the process and lower the negative effect of smartphones and web services on teenagers and kids, to gamify the process of learning and acquiring life skills and useful knowledge. For this task DuoLingo seems to be a perfect tool. 
Modern applications can also be used to (2) give tasks during the lesson and give homework. This can make the education process more effective. This is supposed to be achieved through combining traditional and modern ways of education.

Using the existing applications can (3) be a pedagogical tool to foster the creativity of our learners through activating imagination, as it is implied in Memrise. This may also make the brain activity run faster and thus open an opportunity for further academic research in this sphere.

The real-life videos present (4) a powerful instrument to be applied to make the education process interesting and exciting. However, this requires a further study on a large scale to achieve ultimate research conclusions.

\section{Conclusions}

The present study has given an opportunity to explore three different modern digital applications for teaching foreign languages: DuoLingo, Memrise and FluentU. The services available represent a set of exercises and practical ways to learn a foreign language.

The scientific research conducted has provided an opportunity to explore the practical ways to use and study existing modern applications from the perspective of modern pedagogy.

The research which has been conducted opens a significant perspective for further deep and broad research of practical effects to be achieved through using existing applications for teaching a foreign language. This can make it possible to develop a whole new set of exercises for pupils and students.

\section{References}

1. M. Abbasova, N. Mammadova. The Role of Digital Technology in English Language Teaching in Azerbaijan // International Journal of English Linguistics. - 2019. - Vol. 9. DOI 10.5539/ijel.v9n2p364.

2. M. Warschauer, R. Kern. Theory and practice of network-based language learning // Network-based language teaching: Concepts and practice. Cambridge: Cambridge University Press, 2010. - P. 1-19 
3. H. J. Shin, J. B. Son. EFL teachers' perceptions and perspectives on internet assisted language teaching. // Computer-Assisted Language Learning Electronic Journal (CALL-EJ). - 2007. - Vol. 9. 8(2). — Retrieved from http://callej.org/journal/8-2/h-js_j-bs.html

4. A. Quezada. PSchools in the context of E-education and e-society. 12th Iberian Conference on Information systems and technologies. Lisbon, Portugal 2017. 